\title{
THE NUMERICAL SOLUTION OF STEFAN PROBLEMS WITH FRONT-TRACKING AND SMOOTHING METHODS
}

BY

G. H. MEYER

This work was supported in part by the Science Research Council Grant B/RG/74266 made to Brunei University to finance a Symposium on Finite Element Methods during the period January - June 1975. 
The Numerical Solution of Stefan Problems With Front-Tracking And Smoothing Methods

1. Introduction. The term Stefan (or Stefan type) problem refers to a parabolic initial/boundary value problem involving standard data on the given boundaries as well as Cauchy data on an a-priori unknown and moving boundary or interface. Such problems arise in a diversity of applications and as a consequence they have received considerable attention in the scientific and technical literature. For a wide ranging discussion of the origin, numerical solution and mathematical properties of such problems we refer to the monograph of Rubinstein [29] and the proceedings of a recent conference on Stefan type problem [26]. Moreover, interest in the subject, particularly from the finite element and variational inequality point of view remains undiminished ([4],[6],[11]) .

For the numerical solution of Stefan problems numerous algorithms have been proposed. Most of them are special purpose techniques. Some apply only to one dimensional problems (such as the method of lines [3]) or to special equations and boundary conditions (Greens function methods), while other require a-priori a certain monotonicity or regularity of the solution (as in the isotherm migration method [8] or the heat balance method [16]). Consequently, it is difficult to compare and judge the value of different numerical methods, and general surveys for such methods tend to be open ended [10]. 
It is not the purpose of this paper to compare numerical methods for Stefan problems. Instead, we should like to concentrate on two specific and essentially unrelated numerical methods which have been described earlier [17],[18] and which have proved useful for a variety of Stefan type problems. The first of these methods so far has been used primarily for one dimensional free boundary and interface problems where the free surface varies smoothly with time. As a compensation for this restriction the method is found to be applicable to general free boundary/interface problems for one dimensional linear parabolic equations and not just the Stefan problem. The second method is specific to Stefan problems but unaffected by the number of thermal phases or the dimension of the space. The main intent of this paper is to give some comments on the applicability, performance, and limitations of these methods and, whenever possible, to relate them to other methods proposed for Stefan (type) problems.

2. One dimensional Stefan problems. As a basis for our discussion we shall choose the equations for a two phase Stefan problem on an interval $\left[b_{,}, b_{2}\right]$ with the free interface $s(t)$. The equations of this model problem are

$$
\begin{aligned}
& \frac{\partial}{\partial \mathrm{x}}\left(\mathrm{k}_{1}(\mathrm{x}, \mathrm{t}) \frac{\partial \mathrm{u}_{1}}{\partial \mathrm{x}}\right)-\mathrm{c}_{1}(\mathrm{x}, \mathrm{t}) \frac{\partial \mathrm{u}_{1}}{\partial \mathrm{t}}=\mathrm{F}_{1}(\mathrm{x}, \mathrm{t}), \mathrm{b}_{1}<\mathrm{x}<\mathrm{s}(\mathrm{t}), \mathrm{t}>0 \\
& \frac{\partial}{\partial \mathrm{x}}\left(\mathrm{k}_{2}(\mathrm{x}, \mathrm{t}) \frac{\partial \mathrm{u}_{2}}{\partial \mathrm{x}}\right)-\mathrm{c}_{2}(\mathrm{x}, \mathrm{t}) \frac{\partial \mathrm{u}_{2}}{\partial \mathrm{t}}=\mathrm{F}_{2}(\mathrm{x}, \mathrm{t}), \mathrm{s}(\mathrm{t})<\mathrm{x}<\mathrm{b}_{2}, \mathrm{t}>0
\end{aligned}
$$


subject to prescribed initial/boundary data. In order to demonstrate how Dirichlet and Neumann data are handled we shall impose the following boundary conditions

$$
\mathrm{u}_{1}\left(\mathrm{~b}_{1}, \mathrm{t}\right)=\beta_{1}(\mathrm{t}) \quad \frac{\partial \mathrm{u}_{2}}{\partial \mathrm{x}} \quad\left(\mathrm{b}_{1}, \mathrm{t}\right)+\alpha_{1}(\mathrm{t}), \quad \mathrm{t}>0
$$

$$
\frac{\partial \mathrm{u}_{2}}{\partial \mathrm{x}}\left(\mathrm{b}_{2}, \mathrm{t}\right)=\beta_{2}(\mathrm{t}) \mathrm{u}_{2}\left(\mathrm{~b}_{2}, \mathrm{t}\right)+\alpha_{2}(\mathrm{t}), \quad \mathrm{t}>0
$$

On the free interface $s(t)$ we shall prescribe the following conditions

$$
\begin{gathered}
\mathrm{u}_{1}(\mathrm{~s}(\mathrm{t}), \mathrm{t})=\mu_{1}(\mathrm{~s}(\mathrm{t}), \mathrm{t}) ; \mathrm{u}_{2}(\mathrm{~s}(\mathrm{t}), \mathrm{t})=\mu_{2}(\mathrm{~s}(\mathrm{t}), \mathrm{t}) \\
\left(\mathrm{k}_{1}(\mathrm{~s}(\mathrm{t}), \mathrm{t}) \frac{\partial \mathrm{u}_{1}}{\partial \mathrm{x}}(\mathrm{s}(\mathrm{t}), \mathrm{t})\right)-\left(\mathrm{k}_{2}(\mathrm{~s}(\mathrm{t}), \mathrm{t}) \frac{\partial \mathrm{u}_{2}}{\partial \mathrm{x}}(\mathrm{s}(\mathrm{t}), \mathrm{t})\right) \\
+\lambda(\mathrm{s}(\mathrm{t}), \mathrm{t}) \frac{\mathrm{ds}}{\mathrm{ds}}=\mu_{3}(\mathrm{~s}(\mathrm{t}), \mathrm{t})
\end{gathered}
$$

It may be noted that the only coupling between $\mathrm{u}_{1}$ and $\mathrm{u}_{2}$ is provided by equation (2.1f). Should the function $\mathrm{u}$ be known a priori to the right or left of the interface $s(t)$ (such as $\mathrm{u}_{2} \equiv 0$ for $\left.\mathrm{x} \geq \mathrm{s}(\mathrm{t})\right)$ the above problem reduces to the one phase Stefan problem.

It will be assumed that all data functions are at least continuous on their domain of definition, and that they rule out the appearance of multiple free interfaces. (Criteria for the existence of a unique free interface for the classical Stefan problem may be found, for example, in [17].) However, 
the numerical method does not require consistency of the data at $(x, t)=\left(b_{i}, 0\right), i=1,2$, nor is the specific form of the free interface equations $(2.1 \mathrm{e}, \mathrm{f})$ important. We simply require three equations linking the unknown quantities $\mathrm{u} .\{\mathrm{s}(\mathrm{t}), \mathrm{t}), \frac{\partial \mathrm{u}_{\mathrm{i}}}{\partial \mathrm{x}}(\mathrm{s}(\mathrm{t}), \mathrm{t}), \quad \mathrm{i}=1,2$ and $\mathrm{s}(\mathrm{t}), \quad$ Finally it may be observed that the following development does not depend on the self-adjointness of the elliptic part of $(2.1 \mathrm{a}, \mathrm{b})$. As indicated in [21] convection terms can be included without further difficulty.

The numerical method suggested here for (2.1a-f) requires a time discretization with the method of lines which reduces the above parabolic problem to a sequence of free interface problems for ordinary differential equations. If one chooses the implicit Euler method the sequence of problems at the nth time level may be written as

$$
\begin{aligned}
& \left(\mathrm{k}_{\mathrm{i}} \mathrm{u}_{\mathrm{i}}^{\prime}\right)^{\prime}-\mathrm{c}_{\mathrm{i}} \quad \frac{\mathrm{u}_{\mathrm{i}}-\mathrm{v}_{\mathrm{i}}(\mathrm{x})}{\Delta \mathrm{t}}=\mathrm{F}_{\mathrm{i}} \mathrm{i}=1,2 \\
& \mathrm{u}_{1}\left(\mathrm{~b}_{1}\right)=\beta_{1} \mathrm{u}_{1}^{\prime}\left(\mathrm{b}_{1}\right)^{+} \alpha_{1} \\
& \mathrm{u}_{2}^{\prime}\left(\mathrm{b}_{2}\right)=\beta_{2} \mathrm{u}_{2}\left(\mathrm{~b}_{2}\right)+\alpha_{2} \\
& \mathrm{u}_{1}(\mathrm{~s})=\mu_{1}, \mu_{2}(\mathrm{~s})=\mu_{2},\left(\mathrm{k}_{1} \mathrm{u}_{1^{\prime}}(\mathrm{s})+\mathrm{k}_{2} \mathrm{u}_{2}^{\prime}(\mathrm{s})\right. \\
& \left.+\lambda \frac{\mathrm{s}-\mathrm{s}_{\mathrm{n}-1}}{\Delta \mathrm{t}}\right)=\mu_{3}
\end{aligned}
$$

where ${ }^{\prime} \equiv \frac{\mathrm{d}}{\mathrm{dx}}, \Delta \mathrm{t}=\mathrm{t}_{\mathrm{n}}-\mathrm{t}_{\mathrm{n}-1}$ and where all coefficients and 
source terms are evaluated at $t=t_{n}$. The functions $v_{i}$. denote $u_{i}$ at the previous time level or their linear extensions beyond their domain of definition. They become necessary in order to cope with the curved free interface. For example, let us set $\mathrm{s}\left(\mathrm{t}_{\mathrm{n}}\right)=\mathrm{s}_{\mathrm{n}}{ }^{\prime} \mathrm{u}\left(\mathrm{x}, \mathrm{t}_{\mathrm{n}}\right)=\mathrm{u}(\mathrm{x})_{\mathrm{n}}$ and consider the following geometry

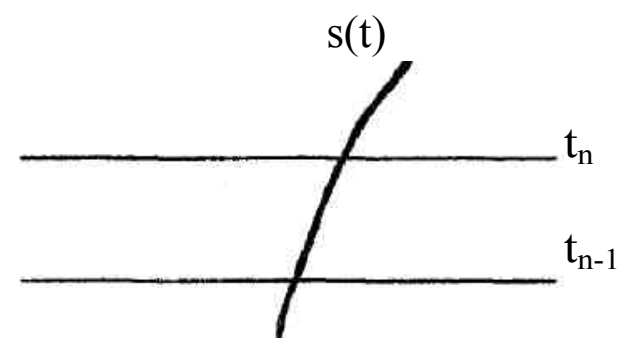

In order to compute $\mathrm{u}_{1}$ over $\left[\mathrm{b}_{1}, \mathrm{~s}_{\mathrm{n}}\right]$ the function $\mathrm{v}_{1}(\mathrm{x})$ is needed over $\left[b_{1}, s_{n}\right]$. If we set

$$
\mathrm{v}_{1}(\mathrm{x})=\left\{\begin{array}{l}
\left(\mathrm{u}_{1}(\mathrm{x})\right)_{\mathrm{n}-1}, \mathrm{x} \varepsilon\left[\mathrm{b}_{1}, \mathrm{~s}_{\mathrm{n}-1}\right) \\
\left(\mathrm{u}_{1}\left(\mathrm{~s}_{\mathrm{n}-1}\right)\right)_{\mathrm{n}-1}+\left(\mathrm{u}_{1}^{\prime}\left(\mathrm{s}_{\mathrm{n}-1}\right)\right)_{\mathrm{n}-1}\left(\mathrm{x}-\mathrm{s}_{\mathrm{n}-1}\right), \mathrm{x} \geq \mathrm{s}_{\mathrm{n}-1}
\end{array}\right.
$$

then it follows from a Taylor series expansion (around $\left(s_{n \_1}, t_{n}\right)$ if $\left.x \in \quad\left[s_{n_{-} 1}, s_{n}\right]\right)$ that the expression (2.2) defines a consistent approximation of order At to the Stefan problem.

The question now arises whether the order can be improved by changing over to a Crank - Nicolson type formula. One possible way of accomplishing this is a smooth continuation of $\left(\mathrm{u}_{\mathrm{i}}\right)_{\mathrm{n}-1}$ as a cubic to handle the curved boundary, and to approximate $s(t)$ with a quadratic Lagrange polynomial. For example, given that $s_{n}>s_{n-1}$, we can define 


$$
\mathrm{v}_{1}(\mathrm{x})=\left\{\begin{array}{r}
\mathrm{u}_{1}(\mathrm{x})_{\mathrm{n}-1}, \mathrm{x} \varepsilon\left[\mathrm{b}_{1}, \mathrm{~s}_{\mathrm{n}-1}\right) \\
\left.\mathrm{u}_{1}\left(\mathrm{~s}_{\mathrm{n}-1}\right)\right) \mathrm{n}-1+\left(\mathrm{u}_{1}{ }^{\prime}\left(\mathrm{s}_{\mathrm{n}-1}\right)_{\mathrm{n}-1}\left(\mathrm{x}-\mathrm{s}_{\mathrm{n}-1}\right)+\frac{1}{2}\left(\mathrm{u}_{1}{ }^{\prime}(\mathrm{sn}-1)_{\mathrm{n}-1}\left(\mathrm{x}-\mathrm{s}_{\mathrm{n}-1}\right)^{2}\right.\right. \\
+\frac{1}{6}\left(\mathrm{u}_{1}{ }^{\prime \prime}\left(\mathrm{s}_{\mathrm{n}-1}\right)_{\mathrm{n}-1}\left(\mathrm{x}-\mathrm{s}_{\mathrm{n}-1}\right)^{3},\right. \\
\mathrm{x} \geq \mathrm{s}_{\mathrm{n}-1}
\end{array}\right.
$$

and write the Crank-Nicolson approximation

$$
\begin{aligned}
\frac{1}{2}\left\{\left(\mathrm{k}_{1} \mathrm{u}_{1}^{\prime}\right)^{\prime} \mathrm{n}+\left(\mathrm{k}_{1} \mathrm{~V}_{1}^{\prime}\right)^{\prime}{ }_{\mathrm{n}-1}\right\} & -\mathrm{c}_{1} \frac{\mathrm{u}_{1}-\mathrm{v}_{1}}{\Delta \mathrm{t}} \\
& =\frac{1}{2}\left\{\left(\mathrm{~F}_{1}\right)_{\mathrm{n}}+\left(\mathrm{F}_{1}\right)_{\mathrm{n}-1}\right\}
\end{aligned}
$$

On $\left[b_{1}, s_{n-1}\right]$ this is the usual Crank-Nicolson expression. If $\mathrm{x} \varepsilon\left(\mathrm{s}_{\mathrm{n}-1}, \mathrm{~S}_{\mathrm{n}}\right)$ then a substitution of the classical solution $\left\{\mathrm{u}_{1}(\mathrm{x}, \mathrm{t}), \mathrm{s}(\mathrm{t})\right\}$ into the expression (2.3) and a Taylor expansion around $\left(\mathrm{s}_{\mathrm{n}-1}, \mathrm{t}_{\mathrm{n}-1}+\frac{1}{2} \Delta \mathrm{t}\right)$ shows that (2.3) is a second order approximation of (2.1a) on $\left(\mathrm{s}_{n-1}, \mathrm{~s}_{\mathrm{n}}\right)$. An improved order of the free interface approximation may be obtained if $s(t)$ is replaced by the quadratic Lagrange polynomial through $\mathrm{s}_{\mathrm{n}-1} \cdot \mathrm{s}_{\mathrm{n}-1}$, and $\mathrm{s}$. If $\mathrm{t}_{\mathrm{n}-1}-\mathrm{t}_{\mathrm{n}-2}=\mathrm{t}_{\mathrm{n}}-\mathrm{t}_{\mathrm{n}-1}=\Delta \mathrm{t}$ then the interface condition correct to order $\Delta t^{2}$ is as follows

$$
\mathrm{u}_{1}(\mathrm{~s})=\mu_{1, \mu_{2}}(\mathrm{~s})=\mu_{2}, \quad\left(\mathrm{k}_{1} \mathrm{u}_{1}{ }^{\prime}(\mathrm{s})+\mathrm{k}_{2} \mathrm{u}_{2}{ }^{\prime}(\mathrm{s})\right.
$$

$$
+\lambda \frac{s_{n-2}-4 s_{n-1}+3 s_{n}}{2 \Delta t}=\mu_{3}
$$

The second order method defined by $(2.3,4)$ has not been tested numerically; however, it is doubtful that such complicated equations can be recommended, particularly since $\mathrm{u}^{\prime \prime}$ is 
not routinely available and since the method is not self-starting, and also in view of the common observation that the Crank-Nicolson method may show oscillations in problems with inconsistent initial/boundary data. Indeed numerical evidence with the implicit Euler method points the other way. Little difference in the numerical performance of the algorithm was observed if $\mathrm{v}_{\mathrm{i}}(\mathrm{x})$ was continued as a constant past the free interface although in this case the approximation (2.2) is not formally consistent on $\left[\mathrm{s}_{\mathrm{n}-1}, \mathrm{~s}_{\mathrm{n}}\right]$. If a higher order method is necessary the finite element approach of [4] in the $(x, t)$-plane may merit consideration. In our own work the first order method (2.2) has always shown an acceptable numerical performance. Given a method of lines discretization, here always sug gested to be $(2.2)$, the Stefan problem is reduced to finding the free interfaces for a sequence of ordinary differential equations. Since these equations are linear it has been proposed repeatedly to determine their fundamental solutions and a particular integral and to combine them in such a way as to satisfy the boundary conditions. But as indicated in [17], one may experience numerical instabilities with this approach. Instead, the method of invariant imbedding (also called the sweep or factorization method) is suggested which is known here to be stable under persistent perturbations [2] and which leads to a stable process for determining the free interface. The last assertion has always been observed in practice and has been (partially) proven for a one phase Stefan problem [30]. 
The method has been described in great detail in [21] and we shall only list the steps of the solution algorithm. The starting point is the use of the Riccati transformations (at time level $t_{n}$ )

$$
\begin{gathered}
\mathrm{u}_{1}(\mathrm{x})=\mathrm{U}(\mathrm{x}) \Phi_{1}+\mathrm{w}(\mathrm{x}) \\
\Phi_{2}(\mathrm{x})=\mathrm{R}(\mathrm{x}) \mathrm{u}_{2}(\mathrm{x})+\mathrm{z}(\mathrm{x})
\end{gathered}
$$

where $\Phi_{\mathrm{i}}(\mathrm{k})=\mathrm{k}_{\mathrm{i}}\left(\mathrm{x}, \mathrm{t}_{\mathrm{n}}\right) \mathrm{u}_{\mathrm{i}}{ }^{\prime}$, and where $\mathrm{U}, \mathrm{w}, \mathrm{R}$, and $\mathrm{z}$ are given on $\left[b_{1}, b_{2}\right]$ as the solutions of the initial value problems

$$
\begin{gathered}
\mathrm{U}^{\prime}=\frac{1}{\mathrm{k}_{1}\left(\mathrm{x}, \mathrm{t}_{\mathrm{n}}\right)}-\frac{\mathrm{c}_{1}\left(\mathrm{x}, \mathrm{t}_{\mathrm{n}}\right)}{\Delta \mathrm{t}} \mathrm{U}^{2}, \mathrm{U}\left(\mathrm{b}_{1}\right)=\beta_{1}\left(\mathrm{t}_{\mathrm{n}}\right) \\
\mathrm{w}^{\prime}=-\frac{\mathrm{c}_{1}\left(\mathrm{x}, \mathrm{t}_{\mathrm{n}}\right)}{\Delta \mathrm{t}} \mathrm{U}(\mathrm{x})\left(\mathrm{w}-\mathrm{v}_{1}(\mathrm{x})\right)-\mathrm{U}(\mathrm{x}) \mathrm{F}_{1}\left(\mathrm{x}, \mathrm{t}_{\mathrm{n}}\right), \mathrm{w}\left(\mathrm{b}_{1}\right)=\alpha_{1}\left(\mathrm{t}_{\mathrm{n}}\right) \\
\mathrm{R}^{\prime}=\frac{\mathrm{c}_{2}\left(\mathrm{x}, \mathrm{t}_{\mathrm{n}}\right)}{\Delta \mathrm{t}}-\frac{1}{\mathrm{k}_{2}\left(\mathrm{x}, \mathrm{t}_{\mathrm{n}}\right)} \mathrm{R}^{2}, \mathrm{R}\left(\mathrm{b}_{2}\right)=\beta_{2}\left(\mathrm{t}_{\mathrm{n}}\right) \\
\mathrm{z}^{\prime}=\frac{\mathrm{R}(\mathrm{x})}{\mathrm{k}_{2}\left(\mathrm{x}, \mathrm{t}_{\mathrm{n}}\right)} \mathrm{z}-\frac{\mathrm{c}_{2}\left(\mathrm{x}, \mathrm{t}_{\mathrm{n}}\right)}{\Delta \mathrm{t}} \mathrm{v}_{2}(\mathrm{x})+\mathrm{F}_{2}\left(\mathrm{x}, \mathrm{t}_{\mathrm{n}}\right), \mathrm{z}\left(\mathrm{b}_{2}\right)=\alpha_{2}\left(\mathrm{t}_{\mathrm{n}}\right) .
\end{gathered}
$$

The computation of $\mathrm{U}, \mathrm{W}, \mathrm{R}$, and $\mathrm{z}$ is frequently called the forward sweep (although $\mathrm{R}$ and $\mathrm{z}$ are actually integrated backward in $\mathrm{x}$ ). In order to determine the free interface the representations (2.5) are used. Elimination of $u_{i}$ and $u_{i}$ leads to the conclusion that the free interface $s$ at time $t_{n}$ must be a root of the equation 


$$
\begin{aligned}
\psi(\mathrm{x}) \equiv \frac{\mu_{1}\left(\mathrm{x}, \mathrm{t}_{\mathrm{n}}\right)-\mathrm{w}(\mathrm{x})}{\mathrm{U}(\mathrm{x})}+\left(\mathrm{R}(\mathrm{x}) \mu_{2}\left(\mathrm{x}, \mathrm{t}_{\mathrm{n}}\right)+\mathrm{z}(\mathrm{x})\right. & +\lambda(\mathrm{x}, \mathrm{t}) \frac{\mu\left(\mathrm{x}-\mathrm{s}_{\mathrm{n}-1}\right)}{\Delta \mathrm{t}} \\
-\mu_{3}\left(\mathrm{x}, \mathrm{t}_{\mathrm{n}}\right) & =0
\end{aligned}
$$

Once $s$ at time $t_{n}$ is known the functions $u_{i}$ are obtained from the socalled reverse sweep, where the following equations are to be integrated

$$
\begin{array}{r}
\mathrm{u}_{2}{ }^{\prime}=\frac{1}{\mathrm{k}_{2}\left(\mathrm{x}, \mathrm{t}_{\mathrm{n}}\right)}\left[\mathrm{R}(\mathrm{x}) \mathrm{u}_{2}+\mathrm{z}(\mathrm{x})\right], \mathrm{u}_{2}(\mathrm{~s})=\mu_{2}(\mathrm{~s}), \mathrm{x} \varepsilon\left[\mathrm{s}, \mathrm{b}_{2}\right] \\
\phi_{1}^{\prime}=\mathrm{c}_{1}\left(\mathrm{x}, \mathrm{t}_{\mathrm{n}}\right) \frac{\mathrm{U}(\mathrm{x}) \phi_{1}+\mathrm{w}(\mathrm{x})-\mathrm{v}_{1}(\mathrm{x})}{\Delta \mathrm{t}}+\mathrm{F}_{1}\left(\mathrm{x}, \mathrm{t}_{\mathrm{n}}\right) \\
\phi_{1}(\mathrm{~s})=\frac{\mu_{1}(\mathrm{~s})-\mathrm{w}(\mathrm{s})}{\mathrm{U}(\mathrm{s})}, \mathrm{x} \varepsilon\left[\mathrm{b}_{1}, \mathrm{~s}\right]
\end{array}
$$

and where $\mathrm{u}_{1}$ follows from the Riccati transformation

$$
\mathrm{u}_{1}(\mathrm{x})=\mathrm{U}(\mathrm{x}) \Phi_{1}(\mathrm{x})+\mathrm{w}(\mathrm{x}) .
$$

In this manner to initial data $\left\{\mathrm{u}_{1}(\mathrm{x}, 0), \mathrm{u}_{2}(\mathrm{x}, 0), \mathrm{s}(0)\right\}$ can be advanced from time level to time level.

The mathematical properties of this algorithm depend strongly on the data of the problem. However, under conditions common in liquid/solid heat transfer processes it can be shown that the sweep equations have smooth solutions on $\left[b_{1}, b_{2}\right]$ and that the scalar equation $\psi(\mathrm{x})=0$ has a unique root on $\left[\mathrm{b}_{1}, \mathrm{~b}_{2}\right]$ 
Moreover, under some additional conditions it is known that the method of lines solution converges to the unique solution of the Stefan problem. For details we refer to [17].

In order to implement the method of lines-invariant imbedding approach on a computer, solution methods for the integration of the above initial value problems and for determining the root of $\psi(x)=0$ have to be chosen. If the solutions of the differential equations must be expected to vary rapidly in $\mathrm{x}$ it would appear advisable to use an adaptive high order integrator. Particularly, variable order variable steplength multistep methods (Adams methods) may be useful for the forward sweep because of their ability to express the solution as a function of $\mathrm{x}$ (a polynomial through the computed nodal values) over the range of integration. These functions are necessary in order to solve $\psi(x)=0$, and to integrate the reverse sweep equations which require the solutions of the forward sweep as input data. If a high order single step method like a RungeKutta-Fehlberg method is used, then interpolation through the nodal values is necessary to find the root of $\psi(x)=0$ and to carry out the reverse sweep. For a recent discussion of available methods for initial value problems and the numerical problems in using a sweep method we refer to [13] and [23]. So far, how ever, there has apparently been no attempt to couple the sweep method with an Adams integrator. What numerical results there do exist for the method of lines-invariant imbedding approach to the Stefan problem have been obtained from integrating the 
sweep equations with the standard trapezoidal rule and from linearly interpolation $\psi\{\mathrm{x})$ between the computed nodal values. The overriding advantage of this method is the fact that the reverse sweep can be carried out with only the nodal values of $\mathrm{U}, \mathrm{w}, \mathrm{R}$, and $\mathrm{z}$ so that interpolation is not necessary; in addition, the difference equations for the forward and backward sweeps are at most quadratic in the unkown and can be solved in closed form. As a result a very fast numerical method is obtained. In general, the free interface determined from the piecewise linear approximation of $\psi$ will have a root. $\mathrm{s}$ which does not coincide with the previously selected nodes for the integrator. It is, however, not difficult to modify the difference equations to incorporate $\mathrm{s}$ as an initial point for the reverse sweep. In most of our numerical work an even cruder approach was used where the mesh point nearest to $\mathrm{s}$ was taken as the initial point for the backward sweep. The heat transfer problems tackled so far with this method have exhibited slowly changing temperatures which do not stress at all the numerical method. Fortunately, this regular temperature behavior is more the rule than the exception and accounts for the success of the heat balance method which in fact presupposes a quadratic dependence of the temperature on the space variable. In summary, for many practical problems a first order method of lines approximation coupled with the trapezoidal rule for the resulting sweep equations can provide a simply coded and fast numerical solution technique. Some numerical evidence of this assertion 
may be found in [19] where heat transfer in a layered permafrost is analyzed, and in [17] where a periodic cooling of a sphere is examined.

The main advantage of the above algorithm is not its ability to solve the classical Stefan problem but its flexibility in treating general free surface conditions. In fact, it has been shown that this method applies to any nth order system of linear ordinary differential equations over an unkown interval subject to $\mathrm{n}+1$ boundary and/or interface conditions [21]. In particular, the method can immediately be applied the method of lines approximations obtained from coupled systems of one dimensional diffusion equations arising, for example, in heat and mass transfer [25], in first order chemical reactions [9], or in coupling the boundary conditions through functional conservation relations [22]. Similarly, purely convective systems can be treated [21]. However, equations arising from diffusion problems are especially distinguished because here the resulting Riccati equations have uniformly bounded solutions; thus one always has available invertible Riccati transformations which reduce most common free interface/boundary conditions to a single scalar equation on a bounded interval. Indeed, from a computational point of view the free interface conditions

$$
\mathrm{u}_{1}(\mathrm{~s}(\mathrm{t}), \mathrm{t})=\mathrm{u}_{2}(\mathrm{~s}(\mathrm{t}), \mathrm{t})=\frac{\partial \mathrm{u}_{1}}{\partial \mathrm{x}}(\mathrm{s}(\mathrm{t}), \mathrm{t})-\frac{\partial \mathrm{u}_{2}}{\partial \mathrm{x}}(\mathrm{s}(\mathrm{t}), \mathrm{t})=0
$$

and the radiation condition $\mathrm{u}_{1}(\mathrm{~s}(\mathrm{t}), \mathrm{t})=\mu_{1}(\mathrm{~s}(\mathrm{t}), \mathrm{t})$ 


$$
\mathrm{k}_{2} \frac{\partial \mathrm{u}_{2}}{\partial \mathrm{x}}=\mu_{1}^{4}-\mathrm{u}_{2}^{4}, \mathrm{k}_{1} \frac{\partial \mathrm{u}_{1}}{\partial \mathrm{x}}-\mathrm{k}_{1} \frac{\partial \mathrm{u}_{2}}{\partial \mathrm{x}}+\lambda \frac{\mathrm{ds}}{\mathrm{dt}}=0
$$

lead to the same order of difficulty. The scalar function $\psi$ associated with the first boundary condition (using the same equations and fixed boundary conditions as in (2.1) is

$$
\psi(\mathrm{x}) \equiv \frac{\mu_{1}-\mathrm{w}}{\mathrm{k}_{1} \mathrm{U}}-\frac{\mathrm{R} \mu_{2}+\mathrm{z}}{\mathrm{k}_{2}}=0
$$

while in the second case we obtain

where

$$
\begin{aligned}
& \psi(\mathrm{x}) \equiv \xi(\mathrm{x})-\mu_{1}{ }^{4}+\frac{\xi(\mathrm{x})-\mathrm{z}}{\mathrm{R}}{ }^{4}=0 \\
& \xi(\mathrm{x})=\frac{\mu_{1}-\mathrm{w}}{\mathrm{U}}+\lambda \frac{\left(\mathrm{x}-\mathrm{s}_{\mathrm{n}-1}\right)}{\Delta \mathrm{t}} .
\end{aligned}
$$

Both functions are readily available (numerically) a $\left[b_{1}, b_{2}\right]$ after the forward sweep has been carried out. This ability to treat quite general free boundary/interface conditions in their natural form (i.e. without problem specific transformations) is considered an advantage of this approach.

The major disadvantage of the method is its inability to handle multiple free interfaces which occur, for example, in three-phase thermal systems. At a phase boundary the Riccati transformations (2.5) are discontinuous. At a known interface location the specific form of the interface condition is used to determine new initial values for the sweep equations (for details see [21, Chapter 3]; however, since now the location 
of the interface is not given, no representation (2.5) is available to reduce placing the free interface to the solution of a scalar function. From a practical point of view it is suggested to determine all but the most critical free boundary location through extrapolation and the one remaining point with the above method. However, no numerical experiments based on such algorithm have been carried out so far.

Although free boundary problems are inherently nonlinear they were solvable with the sweep method only because the differential equations and the fixed boundary conditions were linear so that the Riccati transformations (2.5) were valid. If the diffusion equations themselves are nonlinear, a choice must be made as to either applying invariant imbedding as developed for nonlinear problems (see [21]) or to linearize the problem and then use the above algorithm. So far, little information about the numerical solution of free surface problems has been reported and we can merely outline some options.

In order to be specific we shall consider the nonlinear problems

$$
\frac{\partial}{\partial x}\left(k_{i}\left(x, t, u_{i}\right) \frac{\partial u_{i}}{\partial x}\right)-c_{i}(x, t, u) \frac{\partial u_{i}}{\partial t}=F_{i}\left(x, t, u_{i}\right)
$$

$$
\mathrm{f}_{\mathrm{i}}\left(\mathrm{u}_{\mathrm{i}}, \mathrm{b}_{\mathrm{i}}, \mathrm{t}_{\mathrm{i}}\right)=0
$$




$$
\begin{gathered}
\mathrm{u}_{1}(\mathrm{~s}(\mathrm{t}), \mathrm{t})=\mu_{1}, \mu_{2}(\mathrm{~s}(\mathrm{t}), \mathrm{t})=\mu_{2} \\
\mathrm{k}_{1}\left(\mathrm{~s}, \mathrm{t}, \mathrm{u}_{1}\right) \frac{\partial}{\partial \mathrm{x}} \mathrm{u}_{1}-\mathrm{k}_{2}\left(\mathrm{~s}, \mathrm{t}, \mathrm{u}_{2}\right) \frac{\partial}{\partial \mathrm{x}} \mathrm{u}_{2}+\lambda \frac{\mathrm{ds}}{\mathrm{dt}}=\mu_{\cdot 3} .
\end{gathered}
$$

The most common method is the linearization of the differential equations and the fixed boundary conditions . For example, $u_{i}$ appearing in the coefficients and source terms of (2.6a) may be the values at the previous time level or their extrapolation to the new time level. This method is known to converge [3] as $\Delta t \rightarrow 0$. If the errors are intolerably large for practical time steps an iteration involving simple substitution of the computed solution into the coefficients and source terms and resolving the linear equations will be successful if the dependence of $k_{i}, c_{i}$ and $F_{i}$ on $u_{i}$ is of the proper form [20]. More sophisticated and more involved are Newton (quasilinearization) methods which are commonly applied to nonlinear boundary value problems for ordinary differential equations. At any rate, after linearization the invariant imbedding method is applicable to the solution of the free surface problem.

As a simple illustration of linearization the one-phase Stefan problem for the inhomogeneous heat equation with radiative input on the fixed boundary was solved. The equations were 


$$
\begin{gathered}
u_{x x}-u_{t}=F(x, t) \\
\frac{\partial u}{\partial x}(0, t)=u^{4}-\alpha^{4}(t) \\
u(s(t), t)=0, \frac{\partial u}{\partial x} \quad(s(t), t)+\lambda s^{\prime}(t)=\mu_{3}(s(t), t)
\end{gathered}
$$

The boundary condition $\frac{\partial \mathrm{u}}{\partial \mathrm{x}}=\mathrm{u}^{4}-\alpha^{4}$ (t) was linearized with Newton's method as

$$
\frac{\partial u}{\partial x}=4 u_{0}^{3} u-3 u_{0}^{4}-\alpha^{4}\left(t_{n}\right)
$$

where $\mathrm{u}_{0}$ is the value of $\mathrm{u}\left(\mathrm{b}_{\mathrm{i}}, \mathrm{t}_{\mathrm{n}}\right)$ from the previous iteration. The initial value $\mathrm{u}_{0}$ necessary to start the iteration was determined by extrapolation from the boundary values at previous time levels. While in this case the sweep equations remained unchanged for each iteration their initial values had to be changed to $U\left(b_{1}\right)=4 u_{0}^{3}, w\left(b_{1}\right)=-3 u_{0}^{4}-\alpha^{4}\left(t_{n}\right)$ at each iteration. The equations were solved with the trapezoidal rule. If the data $\mathrm{F}, \alpha$ and $\mu_{3}$ were chosen such that $\mathrm{u}(\mathrm{x}, \mathrm{t})=\mathrm{t} \cos ^{2} \mathrm{t}-\mathrm{x}$ was the solution of the Stefan problem, only two iterations per time step were required to obtain numerical convergence to order $10^{-6}$.

In this example, as is common in many practical problems, the iteration at the first time level could use the initial data. Sometimes, however, the initial conditions and the 
boundary conditions are inconsistent; conceivably, the initial condition is now of little value in determining a starting solution for the iteration at the first time level. In this case the invariant imbedding formulation for free surface problems for nonlinear ordinary differential equations as described in [21] and [23] can provide a first solution. This approach involves integrating initial value problems for hyperbolic partial differential equations and is recommended only as a last resort for nonlinear Stefan problems.

3. Multidimensional problems. Without further restrictions on initial and boundary conditions, Stefan problems in two or more dimensions may show a disconcerting lack of regularity which may prevent an application of the front tracking methods which are useful in one space dimension. For example, phase boundaries may disappear, reappear or have corners. Moreover, multiple phases may be present. For this reason it is common practice the reformulate the free boundary/interface problem over a fixed domain by absorbing the free boundary processes into the differential equation. If one defines the enthalpy of a heat transfer process relative to a base temperature $\mathrm{u}_{0}$ as

$$
\mathrm{H}(\mathrm{u})=\int_{\mathrm{u}_{0}}^{\mathrm{u}} \mathrm{c}(\mathrm{v}) \mathrm{dx}
$$

then conductive heat transfer is described by the equation

$$
\nabla \cdot \mathrm{k}(\mathrm{u}, \mathrm{x}, \mathrm{t}) \nabla \mathrm{u}-\frac{\partial}{\partial \mathrm{t}} \rho(\mathrm{u}, \mathrm{x}, \mathrm{t}) \mathrm{H}(\mathrm{u})=\mathrm{F}(\mathrm{u}, \mathrm{s}, \mathrm{t})
$$


where $\mathrm{k}$ is the conductivity, $\rho$ the density, and $\mathrm{c}$ the heat capacity of the medium, and where $\mathrm{F}$ accounts for external sources or sinks. The phase transition is built into $\mathrm{H}$.

For example, in two phase heat transfer

$$
\lim _{u \rightarrow u^{*}-0} H(u)-\lim _{u \rightarrow u^{*+0}} H(u)=L
$$

where $\mathrm{L}$ is the latent heat for the phase change of the medium. It follows immediately from the discontinuity of $\mathrm{H}$ that equation (3.1) is meaningless at the phase transition temperature $\mathrm{u}^{*}$; instead, it must be interpreted in an integrated ("weak") form

$$
\begin{aligned}
& -\int_{0}^{T} \int_{D} F(u, x, t) \phi(x, t) d x d t+\int_{0}^{T} \int_{D}[u(x, t) \nabla \cdot k(u, x, t) \nabla \phi \\
& \left.+\rho(u, x, t) H(u(x, t)) \frac{\partial \phi}{\partial t}\right] d x d t+\int_{0}^{T} \oint_{\partial D} \phi(x, t) k(u, x, t) \frac{\partial u}{\partial n} \\
& \left.-u(x, t) k(u, x, t) \frac{\partial \phi}{\partial n}\right] d x d t+\int_{D} H(u(x, 0)) \phi(x, 0) d x=0
\end{aligned}
$$

where $\Phi$ belongs to the class of smooth test functions which vanish at $\mathrm{t}=\mathrm{T}$ and which is chosen so that all portions of the boundary integral vanish for which no data are given for u. $\mathrm{D}$ in this case is the fixed domain with smooth boundary in which the heat transfer process takes place. Existence and uniqueness proof for multidimensional Stefan problems 
frequently are based on the weak formulation (3.2)

Although equation (3.1) must not be interpreted in the classical sense because of the singularity at the phase boundary it does provide a means for the numerical solution of the Stefan problem. In essence we are now dealing with a nonlinear partial differential equation with a discontinuous coefficient, namely $\mathrm{H}(\mathrm{u})$. Two different approaches have been suggested. Either the discontinuity is retained and numerical methods are formulated to cope with it, or the discontinuity is removed through smoothing or transforming the dependent variable in which case one is faced with a particular nonlinear partial differential.

In the work of Atthey [1] the discontinuity is retained and an explicit method is suggested to advance the temperature from time level to time level. In the case of one space dimension and constant coefficients the Euler method

$$
\rho \frac{\mathrm{H}^{\mathrm{n}+1}\left(\mathrm{u}_{i}\right)-\mathrm{H}^{\mathrm{n}}\left(\mathrm{u}_{i}\right)}{\Delta \mathrm{t}}=\mathrm{k} \frac{\mathrm{u}_{i+1}^{\mathrm{n}}+\mathrm{u}_{i-1}^{\mathrm{n}}-2 \mathrm{u}_{i}^{\mathrm{n}}}{\mathrm{t}}+\mathrm{F}\left(\mathrm{u}_{\mathrm{i}}^{\mathrm{n}}\right)
$$

is suggested where

$$
\mathrm{H}(\mathrm{u})=\left\{\begin{array}{ll}
\mathrm{cu} & \mathrm{u}<\mathrm{u}^{*} \\
\mathrm{cu}+\mathrm{L} & \mathrm{u}>\mathrm{u}^{*}
\end{array},\right.
$$

Here $u_{i}^{n}$ denotes the approximate temperature for $t=t_{n}$ at the grid point $\mathrm{x}_{\mathrm{i}}$ of an a priori chosen grid on a fixed interval. The calculation proceeds from the initial distribution for 
$\mathrm{H}$ and $\mathrm{u}$ by computing the new enthalpy and the new temperature.

If $\mathrm{H}^{\mathrm{n}+1}\left(\mathrm{u}_{\mathrm{i}}\right) \varepsilon\left(\mathrm{cu}^{*}, \mathrm{cu}^{*}+\mathrm{L}\right)$ then the temperature is set equal

to the phase transition temperature $\mathrm{u}^{*}$. This model allows

the existence of zones which have variable enthalpy at $u^{*}$, socalled mushy regions. In the presence of body heating $(\mathrm{F}>0)$ such zones are physically present and it was the expressed purpose in [1] to determine the mushy regions.

Neither the method nor the convergence proof provided for it in [1] depend on the dimension of the space so that this explicit method represents a general purpose code for multidimensional Stefan problems. Its drawback is the stability restriction on the ratio $\Delta \mathrm{t} / \Delta \mathrm{x}^{2}$ which carries over from the well known case for the heat equation as

$$
\frac{\Delta \mathrm{t}}{\Delta \mathrm{x}^{2}}<\lambda_{0}=\rho \mathrm{c} / 2 \mathrm{k}
$$

If one uses the thermal parameters for water, for example, then $\lambda_{0} \approx 725 \mathrm{sec} / \mathrm{cm}^{2}$. Since the ratio on $\Delta \mathrm{t} / \Delta \mathrm{x}$ is decreased by $2^{\mathrm{n}-1}$ where $\mathrm{n}$ is the dimension of the space it is apparent that the explicit method virtually precludes obtaining long term solutions (requiring At of the order of days) with fine spacial resolutions (with $\Delta \mathrm{x}$ of the order of a few centimeters). Thus, for practical problems the impression of Fox [10] is shared that only unconditionally stable, i.e. implicit, methods deserve further attention.

An implicit analog of (3.3) results if all temperatures 
are taken at the $(n+1)$ th time level. It can be shown that the resulting nonlinear system can be solved with a monotonely converging Gauss-Seidel method by adapting the proof of ortega and Rheinboldt on M-functions and nonlinear SOR processes ([27], p. 465) to handle the discontinuity of $\mathrm{H}$. The numerical performance of such an algorithm is not known at this time. (For a convergence proof see [14].)

The second approach for solving the Stefan problem requires smoothing the enthalpy. In this case $\mathrm{H}$ is replaced by a continuous function, for example by

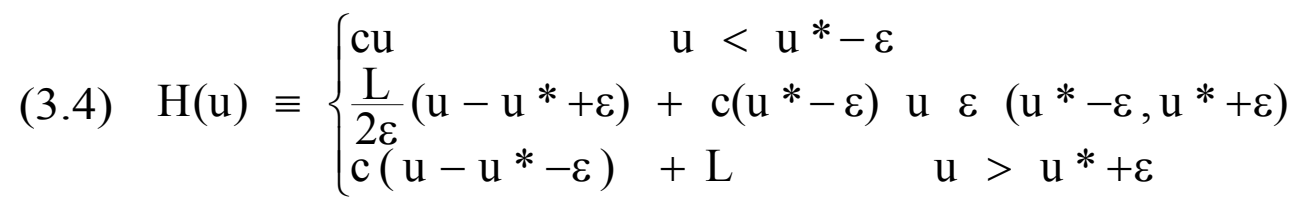

where $\mathrm{e}$ is an a priori chosen tolerance. This model replaces the phase change at the transition temperature $\mathrm{u}^{*}$ with a phase change over the interval $\left(u^{*}-\varepsilon, u^{*}+\varepsilon\right)$. If necessary the density $\rho$ and conductivity $k$ are similarly smoothed out. It may be noted that this formulation is not equivalent to the above since there is no mushy zone over a nonzero interval. The continuous enthalpy has been quite common in work on Stefan problems since it allows the application of classical mathematics to establish the existence, uniqueness and the properties of approximating solutions which then are shown to converge to the weak solution of the Stefan problem. (For 
further details and references on the analytic aspects of Stefan problems we refer to [14] and the many references cited therein.)

While the piecewise differentiable enthalpy still does not allow a pointwise interpretation of (3.1) it is well suited for the numerical solution of the Stefan problem. As in the discontinuous case we time difference the enthalpy to obtain the following sequence of problems

(3.5) $\nabla \cdot \mathrm{k}(\mathrm{u}, \mathrm{x}, \mathrm{t}) \nabla \mathrm{u}-\frac{\rho(\mathrm{u}, \mathrm{x}, \mathrm{t}) \mathrm{H}(\mathrm{u})-\rho\left(\mathrm{u}^{\mathrm{n}}, \mathrm{x}, \mathrm{t}^{\mathrm{n}}\right) \mathrm{H}\left(\mathrm{u}^{\mathrm{n}}\right)}{\Delta \mathrm{t}}=\mathrm{F}(\mathrm{u}, \mathrm{x}, \mathrm{t}), \mathrm{n}=0,1 .$. subject to specified boundary conditions, where $\mathrm{u}$ denotes the unknown temperature at time $\mathrm{t}=(\mathrm{n}+\mathrm{l}) \Delta \mathrm{t}$. At each time level we therefore have to solve a nonlinear elliptic problem of divergence form with a nonlinear source term. We shall write it as

$$
\nabla \cdot \mathrm{k}(\mathrm{u}, \mathrm{x}, \mathrm{t}) \nabla \mathrm{u}-\Phi(\mathrm{u}, \mathrm{x}, \mathrm{t})=0
$$

where both $\mathrm{k}$ and $\Phi$ are continuous functions of $\mathrm{u}$.

The efficient numerical solution of quasilinear equations like (3.6) is still matter of research (see, e.g. [20],[28]. Two different approaches have been explored, finite elements and finite differences. If for ease of exposition we assume that $\mathrm{u}$ is subject to Dirichlet conditions on 3D then both methods may be interpreted as solution techniques for the 
operator $\mathrm{T}$ from the Sobolev space $\mathrm{w}_{0}^{1,2}$ (D) into its dual defined by

$$
\begin{array}{r}
(\mathrm{Tu}, \mathrm{v})=\int_{\mathrm{D}}[\mathrm{k}(\mathrm{u}, \mathrm{x}, \mathrm{t}) \nabla \mathrm{u} \nabla \mathrm{v}+\Phi(\mathrm{u}, \mathrm{x}, \mathrm{t}) \mathrm{v}] \mathrm{dx}=0 \\
\text { for all } \mathrm{v} \varepsilon \mathrm{w}_{0} \mathrm{l}_{1,2} \text { (D) } .
\end{array}
$$

As is well known, finite elements coupled with the Galerkin method require the solution of

$$
\left(\mathrm{Tu}_{\mathrm{m}}, \mathrm{v}_{\mathrm{m}}\right)=0 \quad, \quad \mathrm{v}_{\mathrm{m}} \quad \text { arbitrary },
$$

where $\mathrm{u}_{\mathrm{m}}$ and $\mathrm{v}_{\mathrm{m}}$ belong to a finite dimensional piecewise polynomial subspace of $\mathrm{w}_{0}^{1,2}$ (D) . Finite difference methods provide the solution of

$$
<\mathrm{T}_{\mathrm{m}} \mathrm{u}_{\mathrm{m}}, \mathrm{v}_{\mathrm{m}}>_{\mathrm{m}}=0
$$

where $\mathrm{u}_{\mathrm{m}}, \mathrm{v}_{\mathrm{m}}$ and $\mathrm{T}_{\mathrm{m}}$ are approximations to $\mathrm{u}, \mathrm{v}$, and $\mathrm{T}$ in $\mathrm{a}$ discrete Sobolev space with inner product $<,>_{\mathrm{m}}[18]$.

The existence of solutions for (3.7) and its finite dimensional approximations depend on the structure of $\mathrm{T}$. The ellipticity of (3.6) and some mild growth restrictions on $\mathrm{k}$ coupled with the monotonicity of $\Phi$ suffice to insure the existence of a solution while the divergence form of the equation provides uniqueness. Some analogous results can be 
given for the finite dimensional approximations. However, existence and uniqueness questions are considered here to be secondary to providing constructive useful algorithms for their computation.

Both the Galerkin and the finite difference method lead to a nonlinear system of the form

$$
\mathrm{A}(\mathrm{u}) \mathrm{u}+\mathrm{B}(\mathrm{u})=0
$$

where $\mathrm{A}(\mathrm{u})$ is the discretized elliptic operator $\nabla \cdot \mathrm{k}(\mathrm{u}, \mathrm{x}, \mathrm{t}) \nabla$, and where B depends on $\Phi$ such that the ith equation of (3.10) approximates (3.6) at the ith node or mesh point. It may be noted that for finite elements the ith component of $\mathrm{B}$ involves $\mathrm{N}+1$ unknowns where $\mathrm{N}$ is the number of immediate neighbors of the ith node, whereas for finite differences the ith component of B depends only on $\mathrm{u}_{\mathrm{i}}$; in this case B is said to be diagonal. We shall examine this case in more detail below.

Under assumptions acceptable for heat transfer processes with change of phase it can be shown that the system (3.10) has at least one solution and that Newton's method will locally converge. However, in practice initial values for the diffusion equation are sometimes not consistent with its solution at subsequent times so that good starting values for Newton's method may be difficult to find. Hence globally convergent methods for (3.10) are desireable.

One particularly attractive method for the solution of 
(3.10) is the approximation by mildly elliptic problems which leads to the iteration

$$
\mathrm{A}\left(\mathrm{u}^{\mathrm{n}}\right) \mathrm{u}^{\mathrm{n}+1}+\mathrm{B}\left(\mathrm{u}^{\mathrm{n}+1}\right)=0
$$

where $\mathrm{u}^{0}$ is an arbitrary initial vector (usually the projected solution from the preceding time level). Due to the nonlinearity of $\mathrm{B}$ the equations (3.11) for fixed $\mathrm{n}$ represent a nonlinear system in the unknown $\mathrm{u}^{\mathrm{n}+1}$ which must be solved with a suitable inner iteration; however, such systems have been widely studied and can be solved with a variety of methods. For example, it is known that a Gauss-Seidel method can be used for the inner iteration in which the ith equation of (3.11) is solved for the ith component of $\mathrm{u}$ using the latest values available for the other components of $u$. Each one dimensional equation is nonlinear because $\mathrm{B}$ is nonlinear in $\mathrm{u}$; however, because $\mathrm{B}$ is chosen to be piecewise linear in $\mathrm{u}$ no great difficulty arises in solving the ith equation of (3.11) for the ith component of $\mathrm{u}$.

It is known that the inner Gauss-Seidel iteration converges globally [27], and it has been observed that the rate of convergence can be accelerated through point overrelaxation [18]. The choice of the relaxation parameter is critical for convergence. Published theoretical results [32] do not apply to this problem since B is not convex; in practice it was found that away from the phase transition zone the problem could be 
treated like a standard elliptic problem while in and near the interval $\left(\mathrm{u}^{*}-. \varepsilon, \mathrm{u}^{*}+\varepsilon\right)$ no relaxation was applied to $\mathrm{u}$. If the relaxation parameter was too large a cycling of the inner iteration was observed (for further comment see [7]).

The outer iteration (3.11) together with a Gauss-Seidel or SOR method for the inner iteration is attractive because the system is readily set up since no further derivatives are required. Moreover, it can be shown that if $\mathrm{A}(\mathrm{u})$ is Lipschitz continuous with sufficiently small Lipschitz constant then the iteration (3.11) converges globally to a unique solution of (3.10) (see, e.g. [20] and [28]). At this time not enough numerical evidence exists to indicate whether a small Lipschitz constant for $\mathrm{A}$ is necessary for convergence. If the latter is indeed necessary then (3.11) may not converge for problems with change of phase since $\mathrm{A}(\mathrm{u}) \equiv \mathrm{A}(\mathrm{k}(\mathrm{u}))$ will have a Lipschitz constant proportional to that of the conductivity $\mathrm{k}(\mathrm{u})$ which in the phase transition zone is of the order $\left(\mathrm{k}\left(\mathrm{u}^{*}-\right)-\mathrm{k}\left(\mathrm{u}^{*+}\right)\right) / 2 \varepsilon$, and which becomes unbounded as $\varepsilon \rightarrow 0$. The Lipschitz constant of $\mathrm{B}$ increases likewise in this zone which (loosely) increases the diagonal dominance of (3.10); but the iteration (3.11) may not utilize this fact because $A$ is evaluated at $u^{n}, B$ at $u^{n+1}$ It may be noted that a balancing of these two Lipschitz constants does occur if Newton's method is applied to (3.10) and it is possible to verify that under certain constraints on the ratio of $\frac{\Delta \mathrm{t}}{\Delta \mathrm{x}^{2}}$ a globally convergent continuation method for an operator imbedding like 


$$
\mathrm{H}(\mathrm{u}, \mathrm{t}) \equiv \mathrm{A}(\mathrm{u}) \mathrm{u}+\mathrm{B}(\mathrm{u})+(\mathrm{t}-1) \mathrm{u}_{0}=0, \mathrm{t} \varepsilon,[0,1]
$$

can be defined where $\mathrm{u}_{0}$ is chosen such that $\mathrm{H}(\mathrm{u}, 0)=0$ has an obtainable solution.

The enthalpy approach and related methods based on variational inequalities have been used successfully for the solution of a large number of Stefan type problems. However, they appear unable to cope with those problems where the process on the free surface cannot be absorbed into the differential equation. Source terms like $\mu_{\mathrm{i}}$. in (2.1) or radiative and reactive phenomenon seem to exclude all methods based on fixed-domain considerations since the solution now no longer is determined by its values on the fixed boundary, On the other hand, if the free surface is sufficiently regular then it appears possible to use locally one dimensional (i.e. alternating direction or fractional step) methods to reduce the multi-dimensional problem to a sequence of one dimensional problems. We remark that this approach was used already in [5] and [31] for the classical Stefan problem in its enthalpy form (3.1) and thus still subject to the limitations of fixeddomain methods. An explicit tracking of the free surface in the presence of source terms becomes possible if the invariant imbedding equations are used to solve the one dimensional problems. We are presently examining this technique and can exhibit some preliminary numerical results which seem quite 
promising.

As described in [33] there exist a number of locally onedimensional approximations for multi-dimensional partial differential equations; the expected shape of the free surface will dictate the choice of approximation. If it can be assumed a-priori that the free surface is an invertible function with respect to some rectangular coordinate system then it is possible to apply a direct (non iterative) method. As described in [5] and [31] we simply integrate half the diffusion equation in alternating directions at successive time levels. Extensive numerical experiment with one phase Stefan type problems and implicit problems, (where the gradient of the solution is specified on the free surface) as well as problems with prescribed normal derivative are described in [24]. Moreover, the extension of the alternating direction method to two phase problems with one invertible free interface is immediate. The main limitations of this method are (as in the one dimensional case) its inability to handle directly more than two phases and, of course, the requirement of invertibility. If the motion of the free surface is essentially along one coordinate axis it may be inconvenient or impossible to find a new coordinate system in which the free surface is an invertible function. For such a case an iterative method is suggested which also is capable of handling source terms and nonlinear relations on the free surface. As will be seen, first numerical results with a crude implementation of a Gauss-Seidel type 
algorithm are encouraging. Specifically, we shall consider the one phase model problem

$$
\begin{array}{ll}
\Delta^{\mathrm{u}-}-\frac{\partial \mathrm{u}}{\partial \mathrm{t}}=\mathrm{F}(\mathrm{x}, \mathrm{y}, \mathrm{t}), & 0<\mathrm{x}<\mathrm{x}, 0<\mathrm{y}<\mathrm{s}(\mathrm{x}, \mathrm{t}), \mathrm{t}>0 \\
\mathrm{u}=\mathrm{g}(\mathrm{x}, \mathrm{y}, \mathrm{t}) & \mathrm{x}=0,0 \leq \mathrm{y} \leq \mathrm{s}(0, \mathrm{t}) \\
& \mathrm{x}=\mathrm{x}, \quad 0 \leq \mathrm{y} \leq \mathrm{s}(\mathrm{X}, \mathrm{t}), \mathrm{t}>0 \\
\mathrm{u}=\mathrm{u}_{0}(\mathrm{x}, \mathrm{y}) & \mathrm{y}=0,0<\mathrm{x}<\mathrm{x} \\
& 0<\mathrm{x}<\mathrm{X}, 0<\mathrm{y}<\mathrm{s}(\mathrm{x}, 0)
\end{array}
$$

and the free surface condition

(3.14) $\mathrm{u}=\mu_{1}(\mathrm{x}, \mathrm{y}, \mathrm{t})$

$$
\mathrm{y}=\mathrm{s}(\mathrm{x}, \mathrm{t}), \mathrm{t}>0
$$

$$
\nabla \mathrm{u}=\left(\mu_{2}\left(\mathrm{x}, \mathrm{y}, \frac{\partial \mathrm{x}}{\partial \mathrm{t}}, \mathrm{t}\right), \mu_{3}\left(\mathrm{x}, \mathrm{y}, \frac{\partial \mathrm{y}}{\partial \mathrm{t}}, \mathrm{t}\right)\right)
$$

The one phase Stefan problem is a special case obtained by setting $\mu_{2}=-\lambda \frac{\partial \mathrm{x}}{\partial \mathrm{t}}, \mu_{3}=-\lambda \frac{\partial \mathrm{y}}{\partial \mathrm{t}}$ and $\mu_{1} \equiv 0$.

A simple discretization based on discretizing $\mathrm{x}$ and replacing $\mathrm{u}_{\mathrm{xx}}$ with a central difference quotient has been used so far Let $0=\mathrm{x}_{0}<\mathrm{x},<. .<\mathrm{x}_{\mathrm{n}}=\mathrm{X}$ be a partition of $[0, \mathrm{X}]$ with $\mathrm{x}_{\mathrm{i}}-\mathrm{x}_{\mathrm{i}-1}=\Delta \mathrm{x}$; let , denote $\frac{\mathrm{d}}{\mathrm{dy}}$ and let all time derivatives be replaced by backward difference quotients. Then (3.12-14) at time level $t_{n}$ is approximated by 
(3.15)

$$
\begin{aligned}
& u_{i}^{\prime \prime}-\frac{2}{\Delta x^{2}} u_{i}-\frac{1}{\Delta t} u_{i}=F\left(x_{i}, y, t_{n}\right)-\frac{u_{i-1}+u_{i+1}}{\Delta x^{2}}-\frac{1}{\Delta t} u_{i}\left(y, t_{n-1}\right) \\
& u_{i}(0)=g\left(x_{i}, 0, t_{n}\right)
\end{aligned}
$$

and

$$
\begin{aligned}
& \mathrm{u}_{\mathrm{i}}=\mu_{1}\left(\mathrm{x}_{\mathrm{i}}, \mathrm{s}\left(\mathrm{x}_{\mathrm{i}}, \mathrm{t}_{\mathrm{n}}\right), \mathrm{t}_{\mathrm{n}}\right) \\
& \mathrm{u}_{\mathrm{i}}=\mu_{3}\left(\mathrm{x}_{\mathrm{i}}, \mathrm{s}\left(\mathrm{x}_{\mathrm{i}}, \mathrm{t}_{\mathrm{n}}\right), \frac{\mathrm{s}\left(\mathrm{x}_{\mathrm{i}}, \mathrm{t}_{\mathrm{n}}\right)-\mathrm{s}\left(\mathrm{x}_{\mathrm{i}}, \mathrm{t}_{\mathrm{n}-1}\right)}{\Delta \mathrm{t}}, \mathrm{t}_{\mathrm{n}}\right)
\end{aligned}
$$

for $\mathrm{i}=1, . ., \mathrm{N}-1$. (The free surface equation involving $\mu_{2}$ is simply ignored.) The system (3.15) is solved with a standard SOR method by cycling through the index i . For each i we thus have a one dimensional free surface problem which is solvable in the usual manner with the invariant imbeddir equations. The computed $\mathrm{u}_{\mathrm{i}}$ and $\mathrm{s}\left(\mathrm{x}_{\mathrm{i}}, \mathrm{t}_{\mathrm{n}}\right)$ for (3.15) are adjusted through overrelazation. Although presently no theoretical justification for this procedure is known an acceleration of convergence was observed. The iteration terminates when the free boundary moves less than $10^{-4}$ units between successive SOR sweeps.

In order to gain insight into the performance of this algorithm some numerical experiments were conducted. Two of them will be described here. In both calculations the Riccati equation has a known solution while the remaining invariant imbedding equations were integrated with the trapezoidal rule. All computations were performed with the CDC Cyber 70 
Problem 1. In order to demonstrate that the algorithm can reproduce known solutions the source terms $\mathrm{F}$ and $\mu_{3}$ and the boundary/initial conditions were computed such that (3.12-14) had the solution

$$
\begin{gathered}
\mathrm{u}(\mathrm{x}, \mathrm{y}, \mathrm{t})=\frac{1}{2}(1+\cos (\mathrm{t}-\mathrm{x})-\mathrm{y}) \quad, \quad \mathrm{t} \geq 0,0 \leq \mathrm{x} \leq 3,14,0 \leq \mathrm{y} \leq \mathrm{s}(\mathrm{x}, \mathrm{t}) \leq 1 \\
\mathrm{~s}(\mathrm{x}, \mathrm{t})=\frac{1}{2}(1+\cos (\mathrm{t}-\mathrm{x})) \quad, \quad \mathrm{t} \geq 0
\end{gathered}
$$

Fig. 1 shows a plot of the computed free boundary after each 10 time steps as the system evolves from $t=0$ to $t=3.00$ in 60 time steps. The results shown are valid for $\Delta x=3.14 / 10$, $\Delta y=1 / 20$ and $\Delta t=0.05$ and took about 80 sec. of computer time. Only a slight deterioration was observed if instead $\Delta x=3.14 / 10$, $\Delta \mathrm{y}=1 / 10$ and $\Delta \mathrm{t}=0.1$ was chosen and 30 time steps were carried out. Such a run required 15 sec. and its results are shown after 10, 20 and 30 time steps in Fiqure 2. In both illustrations the upper curve near $\mathrm{y}=1$ is the exact solution $\mathrm{y}=\frac{1}{2}(1+\cos (\mathrm{t}-\mathrm{x}))$. The agreement between the exact and computed free boundaries is apparent.

Problem 2. In order to observe the performance of the algorithm for a classical Stefan problem the melting of a long strip of zinc is modeled. It is assumed that the strip is $100 \mathrm{~cm}$ wide and $4 \mathrm{~cm}$ thick and that both sides and the bottom are insulated. It is also assumed that the strip is initially at 
the phase transition temperature (scaled to be 0 ). If the strip is long it is possible to consider heat transfer in a typical cross section to which the following one phase two dimensional Stefan problem applies

$$
\begin{aligned}
& \mathrm{k}\left(\mathrm{u}_{\mathrm{xx}}+\mathrm{u}_{\mathrm{yy}}\right)-{\mathrm{c} \rho \mathrm{u}_{\mathrm{t}}}=0 \\
& \mathrm{u}(\mathrm{x}, 0, \mathrm{t})=\alpha(\mathrm{x}, \mathrm{t}), \frac{\partial \mathrm{u}}{\partial \mathrm{n}}(0, \mathrm{y}, \mathrm{t})=\frac{\partial \mathrm{u}}{\partial \mathrm{n}}(100, \mathrm{y}, \mathrm{t})=0, \frac{\partial \mathrm{u}}{\partial \mathrm{n}}(\mathrm{x}, 4, \mathrm{t})=0 \\
& \mathrm{ku}_{\mathrm{y}}(\mathrm{x}, \mathrm{s}(\mathrm{x}, \mathrm{t}), \mathrm{t})+\lambda \rho \frac{\mathrm{ds}}{\mathrm{dt}}=0, \\
& \mathrm{u}(\mathrm{x}, \mathrm{y}, 0)=0, \mathrm{~s}(\mathrm{x}, 0)=0 .
\end{aligned}
$$

Here $y=s(x, t)$ denotes the depth to which the zinc has melted. The thermal constants of liquid zinc as reported by Huber [12] are $\mathrm{k}=0.137, \mathrm{c}=0.121, \rho=7.0, \mathrm{~A}=26.6$ in the cgs system. As temperature input on the surface $\mathrm{y}=0$ the linear ramp

$$
\alpha(\mathrm{x}, \mathrm{t})=\mathrm{t} / 300+\max \{100(\mathrm{x}-10) / 80,100\}
$$

was chosen. This problem does not have a known solution: it it was considered solved numerically when further mesh refinements no longer noticeably changed the computed free boundary and mesh refinements.

For this problem the initial and boundary conditions are discontinuous; in fact, the temperature jumps from the phase 
change temperature to 100 degrees above it at the right end of the strip. This is not an easy problem and short time steps are essential. Moreover, quite possibly near the left end a melting from both the top and bottom of the strip may occur since the temperature at the lower left corner is constrained to be fairly low. If this process is to be modeled correctly a change-over to a sweep along the $\mathrm{x}$ direction should be carried out after the free boundary reaches $y=4$. However, as long as $\frac{d y}{d x}<\infty$ the above model and its solution algorithm remain valid. Fig. 3 shows some representative free boundaries for this one phase problem as $\mathrm{t}$ ranges between 0 and $20 \mathrm{sec}$. The results are shown for $\Delta \mathrm{x}=2.5 \mathrm{~cm}, \Delta \mathrm{y}=0.1 \mathrm{~cm}$ and $\Delta \mathrm{t}=2.5 \mathrm{sec}$. Further refinements had little effect. 


\section{References}

1. D. Atthey, A finite difference scheme for melting problems, J. Int. Math. Appl. 13 (1974), pp. 353-366.

2. I. Babuska, M. Prager, and E. Vitasek, Numerical Processes in Differential Equations, Wiley, New York, 1966.

3. R. Bachelis, V. Melamed and D. Shlyaifer, The Solution of the problem of Stefan type by the straight line method, Zh. Vychisl. Mat. mat. Fiz. 9 (1969) pp. 585-594.

4. R. Bonnerot and P. Jamet, A second order finite element method for the one dimensional Stefan problem, Int. J. Num. Meth. Engng. 8 (1974), pp. 811-820.

5. B. Budak, E. Soboleva, and A. Uspenskii, A difference method with coefficient smoothing for the solution of Stefan problems, Zh. Vychisl. Mat. mat. Fiz, 5 (1965), pp. 828-840.

6. G. Comini, S. Delguidice, R. Lewis and 0. Zienkiewicz, Finite element solution of nonlinear heat conduction problems with special reference to phase change, Int. J. Num. Meth. Engng. 8 (1974), pp. 613-624.

7. E. Couch, H. Keller, and J. W. watts, Permafrost thawing around producing oil wells, J. Can. Pet. Tech., April 1970.

8. J. Crank and R, S. Gupta, Isotherm migration method in two dimensions, Brunei University Technical Report 42, 1974.

9. J. Ewards, private communication.

10. L. Fox, What are the best numerical methods? in Moving Boundary Problems in Heat Flow and Diffusion, G. Ockendon and W. Hodgkins, edts., Clarendon Press, Oxford 1975.

11. A. Friedman and D. Kinderlehrer, A one phase Stefan problem, Indiana U. Math, J. 24 (1975), pp. 1005-1035.

12. A Huber, Uber das Fortschreiten der Schmelzgrenae in einem linearen Leiter, Zamm 19 (1939), pp. 1-20,

13. T. Hull, Numerical solutions of initial value problems for ordinary differential equations, in Numerical solutions of Boundary Value Problems for Ordinary Differential Equations, A. Aziz, edt., Academic Press, N.Y. 1975. 
14. J. Jerone, Nonlinear equations of evolution and the Stefan problem, to appear.

15. H. Keller, Numerical Methods for Two Point Boundary Value Problems, Blaisdell, Walbham, Massachusetts, 1968.

16. D. Langford, The heat balance integral method, Int. J. Heat Mass Transfer 16 (1973), pp. 2424-2428.

17. G. Meyer, A numerical method for the two phase Stefan problem, SIAM J. Num. Anal. 8 (1971), pp. 555-568.

18. G. Meyer, Multi-dimensional Stefan problems, SIAM J. Num. Anal. 10 (1973), pp. 522-538.

19. G. Meyer, H. Keller and E. Couch, Thermal models for roads, airstrips and building foundations in permafront regions, J. Canad. Pet. Tech. 11 (1972), pp. 1-13.

20. G. Meyer, The numerical solution of quasilinear elliptic differential equations, in Numerical Solutions of Nonlinear Algebraic Equations, G. Byrne and C. Hall, edts., Academic Press, N.Y., 1973.

21. G. Meyer, Initial Value Methods for Boundary Value Problems Theory and Application of Invariant Imbedding, Academic Press, N.Y., 1973.

22. G. Meyer, Heat transfer during fluidized-bed coating, Int. J. Num. Meth. Engng. 9 (1975), pp. 669-678.

23. G. Meyer, Invariant imbedding for fixed and free two point boundary value problems, in Numerical Solutions of Boundary Value Problems for Ordinary Differential Equations, A. Aziz, edt., Academic Press, N.Y., 1975.

24. G. Meyer, An alternating direction method for multi-dimensional parabolic free surface problems, to appear.

25. M. D. Mikhailov, Exact solution of temperature and moisture distributions in a porous half-space with moving evaporation point, Int. J. Heat Mass Transfer 17 (1974), pp. 797-804.

26. J. Ockendon and W. Hodgkins, edts., Moving Boundary Problems in Heat Flow and Diffusion, Clarendon Press, Oxford, 1975.

27. J. Ortega and W. Rheinboldt, Iterative Solutions of Nonlinear Equations in Several Variables, Academic Press, N.Y., 1970. 
28. W. C. Rheinboldt, On the solution of some nonlinear equations arising in the application of finite element methods, Proceedings of the Second Finite Element Conference at Brunei, to appear.

29. L. Rubinstein, The Stefan Problem, Transl. Math. Monog. 27, A Solomon transl., Amer. Math. Soc., Providence, R.I., 1971.

30. A. Sachs, Zur Struktur eines Algorithmus zur Losung freier Randwertprobleme parabolischer Differenzialoperatoren, in Lecture Notes, Vol. 395, Springer Verlag 1974.

31. A. Samarskii and B. Moiseyenko, An economic continuous calculation scheme for the Stefan multi-dimensional problem, Zh. Vychisl. Mat. mat. Fix. 5 (1965), pp. 816827.

32. S. Schechter, On the choice of relaxation parameters for nonlinear problems, in Numerical Solutions of Systems of nonlinear Algebraic Equations, G. Byrne and C. Hall, edts., Academic Press, N.Y. 1973.

33. N. Yanenko, Die Zwischenschrittmethode zur LÖsung mehrdimensionaler Probleme der mathematischen Physik, Lecture Notes in Math. Vol. 91, Springer Verlag 1969. 


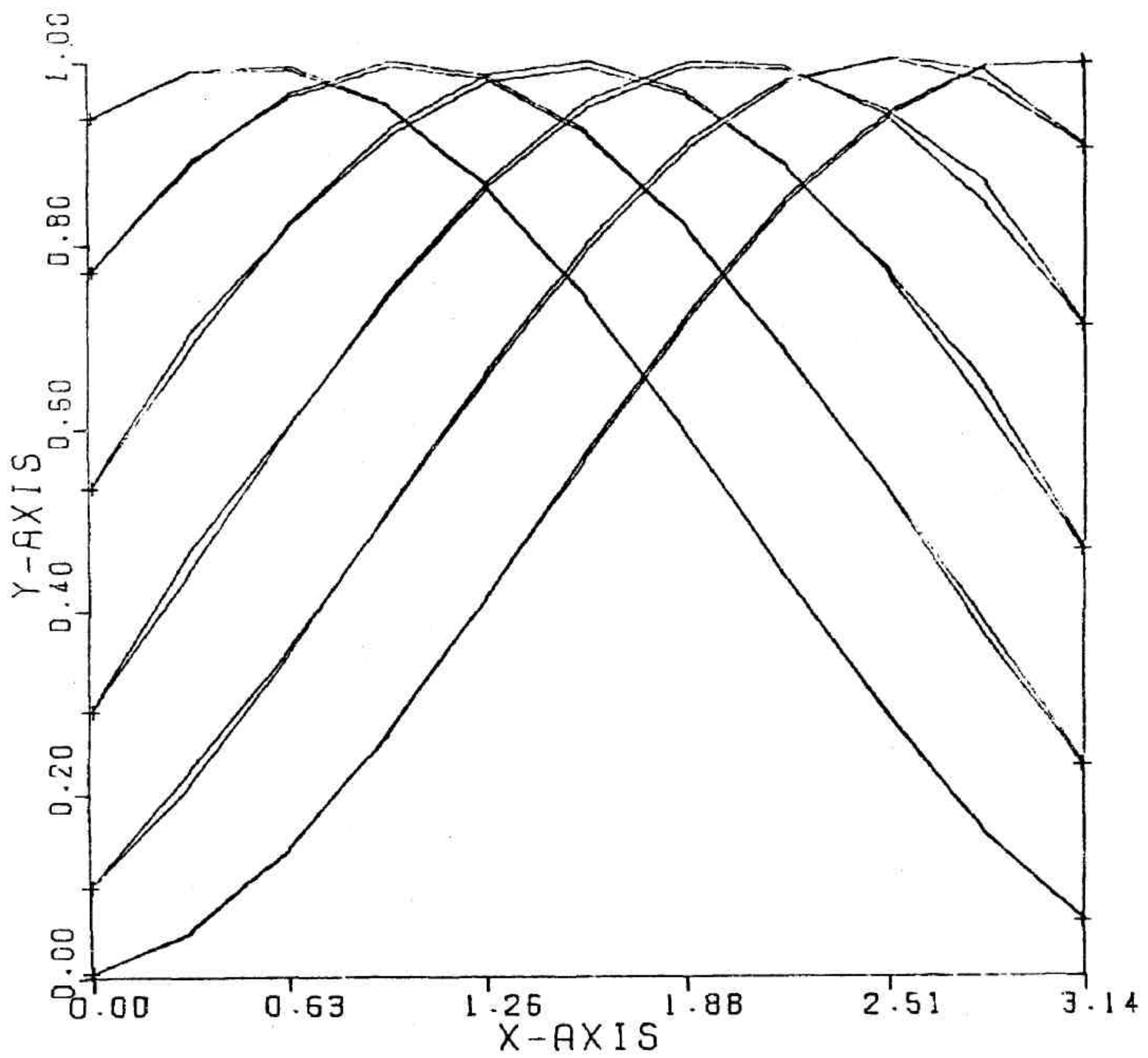

Figure 1. Plot of the computed and exact free surface after each 10 time steps for a Stefan problem with source terms on the free boundary.

Exact solution: $\mathrm{u}(\mathrm{x}, \mathrm{y}, \mathrm{t})=\frac{1}{2}(1+\cos (\mathrm{t}-\mathrm{x})-\mathrm{y}$;

$\mathrm{s}(\mathrm{x}, \mathrm{t})=\frac{1}{2} \cos (\mathrm{t}-\mathrm{x})$

$\Delta \mathrm{x}=3.14 / 10 ; \Delta \mathrm{y}=1 / 20 ; \Delta \mathrm{t}=0.05 ;$

60 time steps, $80 \mathrm{sec}$. CPU time. 


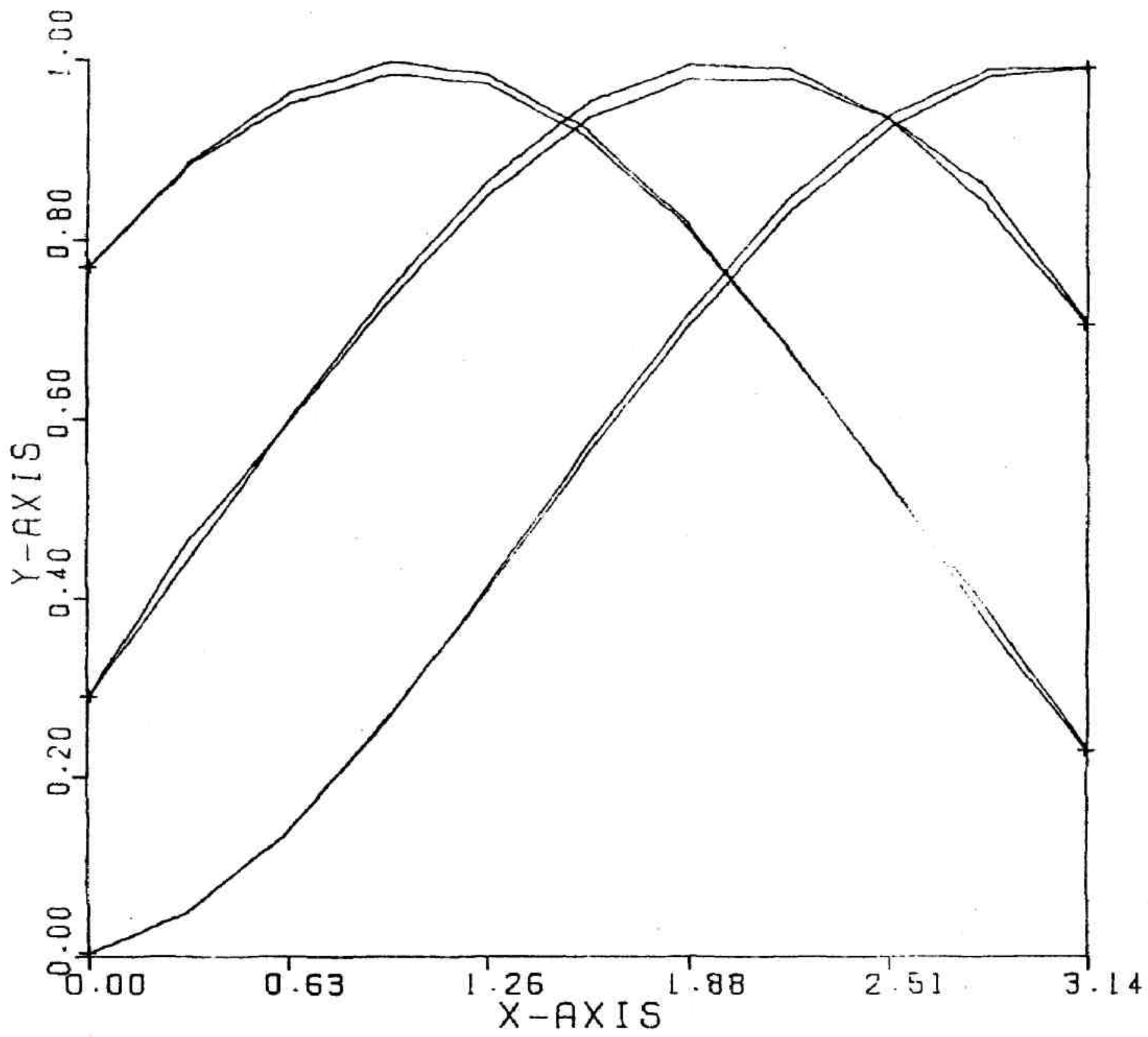

Figure 2. Plot of the computed and exact free surface after each 10 time steps for the mesh

$\Delta \mathrm{x}=3.14 / 10 ; \Delta \mathrm{y}=1 / 10 ; \Delta \mathrm{t}=0.1 ;$

30 time steps, 15 sec. CPU time. 


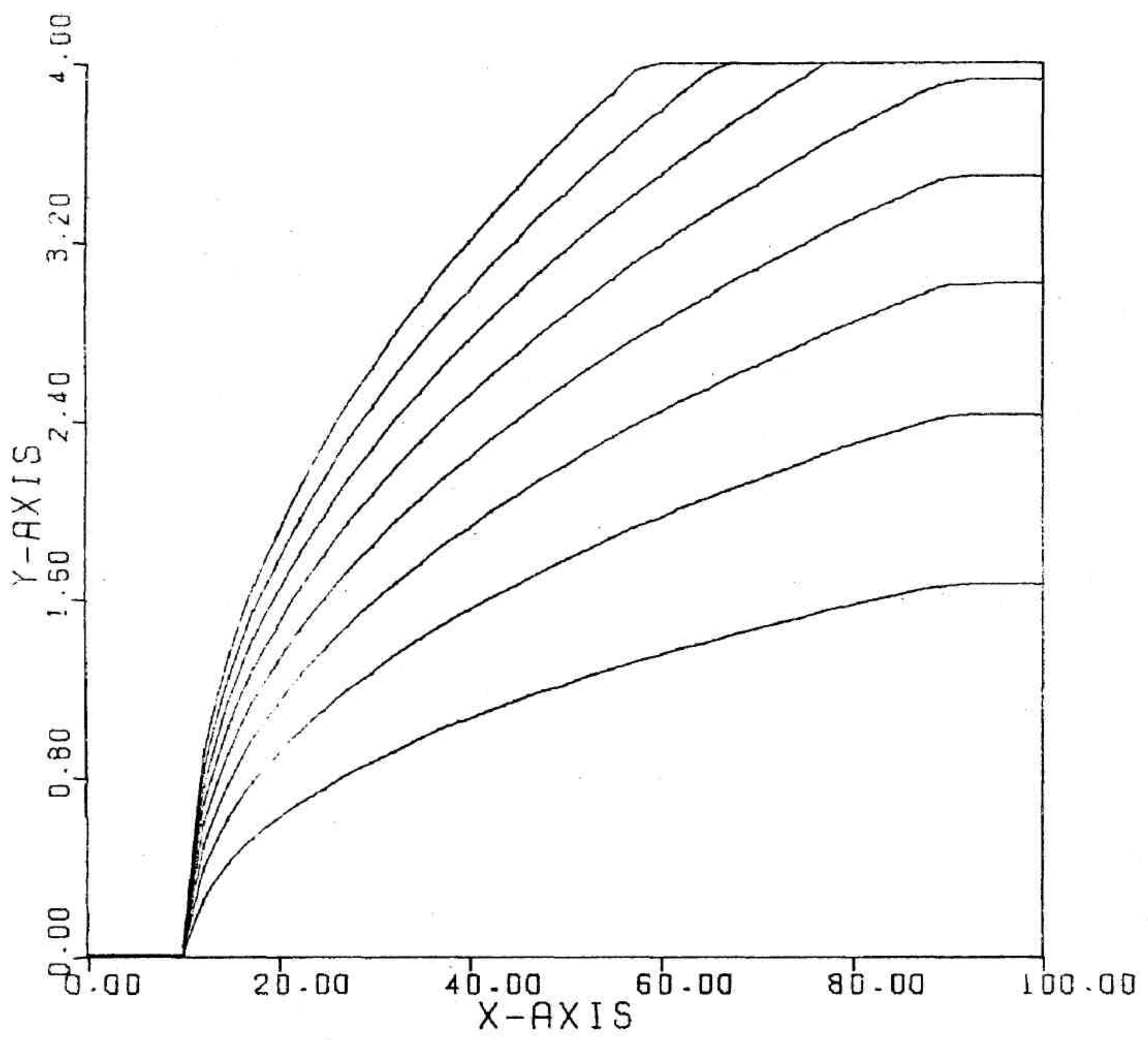

Figure 3. Phase boundaries after each 10 time steps in a $4 \times 100 \mathrm{~cm}$. strip of zinc with a sharp temperature gradient across the surface.

$\Delta \mathrm{x}=2.5 \mathrm{~cm} ; \Delta \mathrm{y}=0.1 \mathrm{~cm} ; \Delta \mathrm{t}=2.5 \mathrm{sec}$;

80 time step, 160 sec. CPU time. 


\section{NOT TO BE \\ REMOVED}

FROM THE LIBRARY

XB 25153072

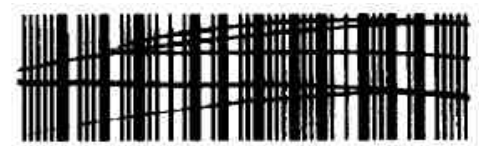

